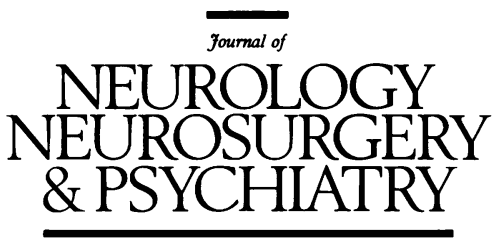

Editorial

\title{
Stroke in pregnancy and the puerperium: what magnitude of risk?
}

Is pregnancy a risk factor for stroke? The risk of ischaemic cerebrovascular events in pregnancy was calculated as 13 times greater than outside pregnancy by Wiebers, ${ }^{1}$ and a five times higher risk of subarachnoid haemorrhage was reported by Fox et al. ${ }^{2}$ Although these excess risks sound impressive, we are concerned that they may not be based on reliable data.

There are at least four major questions in considering stroke in relation to pregnancy: Are the incidence and aetiology of pregnancy related stroke different from those of the general female population of child bearing age? Should the investigative approach be modified for pregnant patients? Does pregnancy increase the risk of stroke events in patients with known vascular lesions? What is the risk of recurrence in future pregnancies? Bearing these questions in mind, it is appropriate to examine the following categories of stroke: $(a)$ ischaemic stroke due to presumed arterial occlusion; (b) intracranial venous thrombosis; (c) intracranial aneurysms (ruptured and unruptured); (d) arteriovenous malformations (ruptured and unruptured); (e) other causes of intracranial haemorrhage.

For each of these, we consider the available evidence about risk, timing, and outcome of stroke. The more specific problem of pre-eclampsia and eclampsia is not considered, being under investigation by the British Eclampsia Survey Team. ${ }^{3}$

\section{Ischaemic stroke due to presumed arterial occlu-} sion

Accurate figures for cerebral infarction during pregnancy are not available. In early series the distinction of arterial from venous cerebral infarction was not clear, and CT was not available. ${ }^{45}$ Jennett and Cross ${ }^{6}$ provided angiographic evidence of arterial occlusion in most of their cases, so challenging the long held concept that pregnancy related neurological events, including strokes, were predominantly of venous origin. Thus early estimates of "cerebral infarction" affecting one in 2000 pregnancies ${ }^{4}$ as reviewed by Wiebers and Whisnant ${ }^{7}$ should now be disregarded. Surprisingly, this failure to distinguish arterial from venous cerebral infarction persists in some recent studies ${ }^{18}$ resulting in a falsely high one in 10000 rate of "cerebral infarction" by including two cases of venous thrombosis in a total of nine pregnancy related ischaemic strokes. ${ }^{8} \mathrm{~A}$ lower frequency of one in 20000 pregnancies $^{9}$ is also unreliable, being calculated from 31 cases studied over 11 years and assuming complete referral to one neurosurgical centre from a scattered population of three million. Statistical interpretation of one stroke in 26000 pregnancies reported from a major regional study is also difficult, as it is based on a single case of cerebral infarction during the 25 year study. ${ }^{7}$

Comparing stroke rates during pregnancy with those of non-pregnant women showed only a marginal excess risk during pregnancy, ${ }^{7}$ and although the population studied was small and the data therefore imprecise, the finding of stroke rates in pregnancy that were "not much different for all women of childbearing age" is an important challenge to the high rates of ischaemic stroke in pregnancy reported elsewhere. It is possible that these high rates have been achieved through referral and selection bias in other published series. Therefore, it is not at all clear that risk of cerebral infarction really is greater during pregnancy. A provisional report from France, albeit retrospective, seems to support this possibility. ${ }^{10}$

Ischaemic strokes seem to be most common in the puerperal period and third trimester, with few cases in the first trimester. ${ }^{8}$ The aetiology of pregnancy related stroke is often difficult to identify. Major arterial occlusion was found angiographically or at post-mortem in just over half of 73 cases in one series; $30 \%$ showed no vascular lesion. ${ }^{9}$ There are no recent large series of pregnancy related ischaemic strokes benefiting from detailed investigation with modern imaging techniques. Common risk factors apply to pregnant patients, and hypertension is the best defined, but premature atheroma is considered causative in only a quarter of strokes in pregnancy. ${ }^{11}$ Whereas the eclampsia syndrome usually includes cerebral complications, hypertension contributes independently to the risk of pregnancy related stroke, especially in older women with chronic background hypertension. ${ }^{12}$

Modern investigation of stroke in pregnant patients should follow guidelines for non-pregnant patients. Magnetic resonance imaging and $\mathrm{CT}$ are appropriate to confirm clinical localisation and separate haemorrhage from infarction. In cases of ischaemic stroke, carotid duplex may usefully identify stenosis, occlusion, or dissection of the carotid artery. Cerebral angiography is sometimes performed, ${ }^{1}$ but there is probably no justification for frequent application as suggested by Donaldson $^{11}$; increasing use of magnetic resonance angiography is likely. A search for rarer causes of stroke linked to pregnancy such as choriocarcinoma, postpartum cardiomyopathy, ${ }^{13}$ paradoxical embolism, hypoten- 
sive boundary zone infarction, and use of ergot may be appropriate. Less clearly pregnancy related cardiac causes (valvar heart disease, endocarditis, rhythm disturbance), haematological disorders (including sickle crisis), and other disorders such as lupus anticoagulant ${ }^{14}$ and homocystinuria ${ }^{15}$ have been reported in a few cases.

A poor outcome has been reported in pregnancy related stroke in comparison with non-pregnant women or men of the same age. ${ }^{89}$ The statistical and design problems discussed also apply to these comparative data. Maternal mortality data are the best available indicator of poor outcome, but do not allow comparison with nonpregnant women. The decline in obstetric complications means that non-obstetric causes of mortality, including stroke, are of greater importance than previously. ${ }^{8}$ Cerebrovascular accident was the cause of 107 of 2475 $(4 \cdot 3 \%)$ maternal deaths in one major national study. ${ }^{16} 17$ In public health terms this number of cases is small (21 per annum within the entire United States) and it includes all types of cerebrovascular accident. ${ }^{1617}$

\section{Intracranial venous thrombosis}

$\mathrm{Up}$ to one third of pregnancy related cerebral infarcts may be due to intracranial venous thrombosis, which is more frequent in the early postpartum period and in the third trimester. The early literature, reviewed by Carroll et $a l^{18}$ and Cross $e t a l^{9}$ recorded an overall risk of between one in 1666 to one in 10000 pregnancies. A lower rate of one in 45000 was based on two cases identified over 6.5 years. ${ }^{8}$ Predisposing factors including dehydration and infection may contribute to intracranial venous thrombosis in pregnancy, but their relative importance and the role of pre-eclampsia ${ }^{18}$ is unclear. Sepsis has been emphasised as a contributor in cases occurring in early pregnancy but is not always present. ${ }^{19}$ The presence of peripheral deep venous thrombosis may point to a diagnosis of intracranial venous thrombosis as the two are associated, but deep venous thrombosis also occurs in angiographically confirmed arterial strokes. ${ }^{9}$

Clinical diagnosis is confirmed by radiological investigation; MRI has greatly improved the diagnosis of major sinus occlusion. ${ }^{2021}$ Anticonvulsants are often used and antibiotics added if there is an infection source. There is some evidence of benefit from anticoagulation ${ }^{20}{ }^{22}$; results of an ongoing multicentre trial are awaited. Many clinicians avoid anticoagulation if there is intracerebral haemorrhage in association with intracranial venous thrombosis, but others use anticoagulants routinely.

\section{Intracranial aneurysms (ruptured and unruptured)}

Two recent American reviews reached conflicting conclusions of a fivefold increased risk ${ }^{2}$ and no increase in risk ${ }^{8}$ of subarachnoid haemorrhage in pregnancy. Absolute risk has been estimated at between one in 2000 and one in 10000 pregnancies. Hunt et al estimated that between 20000 and 40000 women deliver successfully each year in the United States despite harbouring intracranial aneurysms..$^{23}$ If bleeding does occur, it is most likely in the third trimester. ${ }^{23}$ In the non-pregnant state aneurysms are significantly commoner than arteriovenous malformation (AVM) as a cause of subarachnoid haemorrhage. During pregnancy a more even split between these two causes of subarachnoid haemorrhage is reported, and has been attributed to a greater risk of AVM rupture. ${ }^{24} 25$ Aneurysm rupture is described as a "leading cause of maternal mortality in North America", ${ }^{26}$ however, contributing between $6 \%^{27}$ and $12-25 \%^{24} 28$ of cases of maternal mortality, although these figures far exceed the national study quoted. ${ }^{17}$ Screening for aneurysms before pregnancy may not be generally achievable, but seems relevant when a family history is present. Pregnancy was not considered at all in a recent review of the options in aneurysm screening for familial cases. ${ }^{29}$

The management options after subarachnoid haemorrhage in pregnancy are early clipping or delivery (spontaneous or by Caesarean section), with a possible risk of rebleeding during delivery in unclipped cases. ${ }^{3031}$ Caesarean section may be appropriate for patients with an acute bleed who are near term, but management is generally recommended to follow that for the non-pregnant case. ${ }^{2732} \mathrm{~A}$ better outcome has been claimed for cases managed neurosurgically after early diagnosis, ${ }^{824}$ and craniotomy and clipping have been successfully achieved at all stages of pregnancy. ${ }^{232533}$ Overall Amias reported no difference in prognosis between pregnant and non-pregnant cases of subarachnoid haemorrhage. ${ }^{32}$

The optimal management of patients with a known cerebral aneurysm who become pregnant is not clearly established. Of 20 such cases reviewed by Hunt et $a l^{23}$ there were no recurrent haemorrhages during subsequent pregnancies. The authors found little evidence for altering standard obstetric practice in this group, and in particular no indication for elective Caesarean section. There has, however, been no formal approach comparing different treatments.

\section{Arteriovenous malformations (ruptured and unruptured)}

Haemorrhage from arteriovenous malformation is most common during early pregnancy or delivery. ${ }^{24}$ The overall risk of AVM haemorrhage does not seem to increase with pregnancy, however, and was identical at 0.031 per patient year in the pregnant and non-pregnant state in patients without previous bleeding. ${ }^{31}$ In a series of 100 consecutive supratentorial AVM haemorrhages only one patient was pregnant; nine of these 100 cases had uncomplicated previous pregnancies. ${ }^{34} \mathrm{~A}$ low risk of pregnancy related AVM bleeding was also suggested by a review of 70 cases over 20 years; only one pregnant patient bled (during the first trimester of her third pregnancy), and 10 of the 15 women who had children presented outside pregnancy or the puerperal period. ${ }^{30}$ The occurrence of intracranial haemorrhage outside pregnancy in 26 patients with a mean of $2 \cdot 2$ prior uncomplicated pregnancies further questions the role of pregnancy in causing intracerebral bleeding ${ }^{1}$; this group included three cases of AVM with a total of eight uncomplicated pregnancies delivered vaginally.

\section{Other causes of intracranial haemorrhage}

Although intracerebral haemorrhage may arise from aneurysm or AVM rupture, primary bleeding also occurs. It is often attributable to hypertension, which may predate the pregnancy (three of six cases reported by Simolke $e t a l^{8}$ ) and is sometimes due to haematological disease, but may have no obvious aetiology.

\section{Discussion}

The available information about stroke in pregnancy is clearly incomplete. We highlight the following problems:

(1) Subclassification of stroke type has been very poor even at a basic level, with studies failing to distinguish intracranial venous thrombosis from other forms of stroke, particularly other forms of cerebral infarction. In all studies the diagnostic information on the cause of stroke has been very limited. 
(2) Precise estimates of risk cannot be made from the small published numbers. After excluding earlier published series where CT was not performed, patient numbers are very small indeed.

(3) Referral bias has almost always been a problem and can only be investigated by a population based study. The only population study reported to date is of maternal mortality from stroke; these findings need to be extended to non-fatal cases.

(4) There are no follow up studies of any consequence that look at the risk of recurrence in future pregnancies.

These problems have led to the inevitable result that there is no useful information for routine clinical practice except in so far as we know that stroke related to pregnancy is a rare problem, but when it occurs it is a disaster for the whole family.

As individual obstetric units will on average have one case or less per year of pregnancy related stroke, there is limited local experience, and similar restrictions apply to neurological and neurosurgical centres and medical units. Therefore, a national study of stroke in pregnancy is essential to evaluate incidence and recurrence. There is a clear need for large numbers to be studied with prospective and careful investigation in all cases. Assuming a crude birth rate of 10 per 1000 , a stroke risk of one in 2000 pregnancies would mean about 250 pregnancy associated strokes annually in the United Kingdom. If the risk is only one in 26000 then only 20 strokes would be expected.

A national framework for collecting information on rare neurological disorders, the British Neurological Surveillance Unit (BNSU), was established in January 1993. The BNSU has followed the successful pattern set by the Paediatric Surveillance Unit. Reporting of specified neurological conditions that are either unusual or deserve national study is undertaken by members of the Association of British Neurologists and the British Neuropsychiatry Association. Stroke in pregnancy has recently been added to the reportable conditions, with the initial aim of identifying a cohort of 100 women who have had an acute stroke during pregnancy or during the six weeks after delivery. The definition includes any case with deficit exceeding 24 hours that, after adequate investigation, is thought likely to have a vascular basis. All stroke syndromes due to cerebral infarction, primary intracerebral haemorrhage, subarachnoid haemorrhage, and intracranial venous thrombosis are included. Cases with predisposing factors such as hypertension or known arteriovenous malformations will also be included, as will any patient seen within the past 12 months. This will allow us to get some idea of the size of the problem and of the causes of pregnancy related stroke, and will be the beginning of a cohort study of risk of recurrent stroke in future pregnancies.

After this pilot phase we plan a major combined reporting effort to identify all cases of first or recurrent stroke during pregnancy, and agreement of representative bodies of United Kingdom neurologists, neurosurgeons, and obstetricians has been obtained for this project. It may then be possible to examine the excess risk of pregnancy related stroke compared with the expected risk in women of child bearing age.

DONALD G GROSSET University Department of Medicine and Therapeutics, Western Infirmary, Glasgow, UK SHAH EBRAHIM Department of Public Health and Primary Care, Royal Free Hospital School of Medicine, London, UK
IAN BONE

Department of Neurology, Institute of Neurological Sciences, Southern General Hospital, Glasgow, UK CHARLES WARLOW Department of Clinical Netinburgh, UK

Correspondence to: Dr D G Grosset, University Department of Medicine and Therapeutics, Western Infirmary, Glasgow G1 1 6NT, UK

1 Wiebers DO. Ischemic cerebrovascular complications of pregnancy. Arch Neurol 1985;42:1106-13.

2 Fox MW, Harms RW, Davis DH. Selected neurologic complications of pregnancy. Mayo Clin Proc 1990;65:1595-1618.

3 Douglas KA, Redman CWG. Eclampsia in the United Kingdom. The "BEST" way forward. Br F Obstet Gynaecol 1992;99:355-9.

4 Lorincz AB, Moore RY. Puerperal cerebral venous thrombosis. Am 7 Obstet Gynecol 1962;83:311-8.

5 Goldman JA, Eckerling B, Gans B. Intracranial venous sinus thrombosis in pregnancy and puerperium: report of 15 cases. Fournal of Obstetrics in pregnancy and puerperium: report of 15 cases. Fournal

6 Jennett WB, Cross JN. Influence of pregnancy and oral contraception on the incidence of strokes in women of childbearing age. Lance 1967;i:1019-23.

7 Wiebers DO, Whisnant JP. The incidence of stroke among pregnan women in Rochester, Minn, 1955-1979. Fournal of the American Medical Association 1985;254:3055-7.

8 Simolke GA, Cox SM, Cunningham FG. Cerebrovascular accidents complicating pregnancy and the puerperium. Obstet Gynecol 1991;78:37-42.

9 Cross JN, Castro PO, Jennett WB. Cerebral strokes associated with pregnancy and the puerperium. $B M F$ 1968;3:214-8.

10 Sharsar T, Lamy C, Mas JL, for the stroke in pregnancy study group. Incidence and causes of strokes during pregnancy and early puerperium in the region of Ile de France [abstract]. Cerebrovascular Diseases 1994;3:247.

11 Donaldson JO. Neurological problems of pregnancy. In: Bradley WG Daroff RB, Fenichel GM, Marsden CD, eds. Neurology in clinical pracDaroff RB, Fenichel GM, Marsden CD, eds. Neurol
tice. Boston: Butterworth-Heinemann, 1991:809-15.

12 Cunningham FG, Leveno KJ. Management of pregnancy-induced hypertension. In: Rubin PC, ed. Handbook of hypertension. Vol 10: hypertension in pregnancy. Oxford: Elsevier, 1988:209-319.

13 Dyken ME, Biller J. Peripartum cardiomyopathy and stroke. Cerebrovascular Diseases 1994;4:325-8.

14 Branch DW, Silver RM, Blackwell JL, Reading JC, Scott JR. Outcome of treated pregnancies in women with antiphospholipid syndrome: an update of the Utah experience. Obstet Gynecol 1992;80:614-20.

15 Newman G, Mitchell JRA. Homocystinuria presenting as multiple arterial occlusions. $Q \mathcal{F}$ Med 1984;LIII:251-8.

16 Kaunitz AM, Hughes JM, Grimes DA, Smith JC, Rochat RW, Kafrissen ME. Causes of maternal mortality in the United States. Obstet Gynecol 1985;65:605-12.

17 Rochat RW, Koonin LM, Atrash HK, Jewett JF and the maternal mortality collaborative. Obstet Gynecol 1988;72:91-7.

18 Carroll JD, Leak D, Lee HA. Cerebral thrombophlebitis in pregnancy and the puerperium. $Q \mathcal{F}$ Med 1966;35:347-68.

19 Lavin PJM, Bone I, Lamb JT, Swinburne LM. Intracranial venous thrombosis in the first trimester of pregnancy. $\mathcal{F}$ Neurol Neurosurg Psychiatry 1978;41:726-9.

20 Villringer A, Seiderer M, Bauer WM, Laub G, Haberl RL, Einhaupl KM Diagnosis of superior sagittal sinus thrombosis by three dimensional magnetic resonance flow imaging. Lancet $1989 ; \mathbf{i}: 1086-7$.

21 Ameri A, Bousser MG. Cerebral venous thrombosis. Neurol Clin 1992;10:87-111

22 Easton JD. Treatment of cerebral venous thrombosis-issues in stroke. Cerebrovascular Diseases 1993;3:329-32.

23 Hunt HB, Schifrin BS, Suzuki K. Ruptured berry aneurysms and pregnancy. Obstet Gymecol 1974;43:827-37.

24 Robinson JL, Hall CS, Sedzimir CB. Arteriovenous malformations, aneurysms and pregnancy. $\mathcal{F}$ Neurosurg 1974;41:63-70.

25 Minielly R, Yuzpe AA, Drake CG. Subarachnoid hemorrhage secondary to ruptured cerebral aneurysm in pregnancy. Obstet Gynecol to ruptured $1979 ; 53: 64-70$.

26 Zabramski JM, Spetzler RF. Surgery of intracranial aneurysms. In: Barnett HJM, Mohr JP, Stein BM, Yatsu FM, eds. Stroke: pathophysiology diagnosis and management. New York: Churchill Livingstone, 1991:1055-92.

27 Selmar WR, Ratcheson RA. Intracranial aneurysms. In: Bradley WG Daroff RB, Fenichel GM, Marsden CD, eds. Neurology in clinical practice. Boston: Butterworth-Heinemann, 1991:955-69.

28 Mohr JP, Kistler JP, Fink ME. Intracranial aneurysms. In: Barnett HJM Mohr JP, Stein BM, Yatsu FM, eds. Stroke: pathophysiology diagnosis and management. New York: Churchill Livingstone, 1991:617-43.

29 ter Berg HWM, Dippel DWJ, Limburg M, Schievink WI, van Gijn J. Familial intracranial aneurysms. A review. Stroke 1992;23:1024-30.

30 Kelly DL, Alexander E, Davis CH, Maynard DC. Intracranial arteriovenous malformations: clinical review and evaluation of brain scans. $f$ Neurosurg 1969;31:422-8.

31 Horton JC, Chambers WA, Lyons SL, Adams RD, Kjellberg RN. Pregnancy and the risk of hemorrhage from cerebral arteriovenous malformations. Neurosurgery 1990;27:867-72.

32 Amias AG. Cerebral vascular disease in pregnancy I. Haemorrhage. fournal of Obstetrics and Gynaecology of the British Commonwealth fournal of Obsteri

33 Pool $\mathrm{L}$. Treatment of intracranial aneurysms during pregnancy. $\mathfrak{f} A M A$ 1965;192:209-14.

34 Parkinson J, Bachers G. Arteriovenous malformations. Summary of 100 consecutive supratentorial cases. $\mathcal{F}$ Neurosurg 1980;53:285-9. 